\title{
An All-Solid-State Polymeric Membrane chloride ion-selective Electrode with Nanowires poly(3,4-ethylenedioxythiophene) as Solid Contact
}

\author{
Zhe ${ }^{1}{ }^{1}$, Ming Lei ${ }^{2,3}$, Juan Chen ${ }^{1, *}, X i n Q i^{2,3}$ \\ ${ }^{1}$ College of Information Science and Technology, Beijing University of Chemical Technology, \\ Beijing 100029, PR China \\ ${ }^{2}$ College of Science, Beijing University of Chemical Technology, Beijing 100029, PR China \\ ${ }^{3}$ Beijing Key Laboratory of Environmentally Harmful Chemical Analysis, Beijing 100029, PR China \\ *E-mail: jchen@mail.buct.edu.cn
}

doi: $10.20964 / 2017.12 .44$

Received: 21 July 2017 / Accepted: 21 September 2017 / Published: 12 November 2017

\begin{abstract}
This paper reports the development of a novel all-solid-state polymeric membrane $\mathrm{Cl}^{-}$-selective electrode, based on nanowires poly(3,4-ethylenedioxythiophene) (PEDOT) as solid contact. The nanowires PEDOT films are synthesized on the glassy carbon electrode surface by electrochemical galvanostatic method in the cetyltrimethylammonium bromide aqueous solution. The electrochemical performances of nanowires PEDOT films are evaluated by cyclic voltammetry and electrochemical impedance spectroscopy, which indicate that the nanowires PEDOT have large redox capacitance and fast charge-transfer rate. This makes the PEDOT films suitable for solid contact layer of all-solid-state ion selective electrode. With the nanowires PEDOT, the all-solid-state $\mathrm{Cl}^{-}$-selective electrode shows a Nernstian response in the range from $1.0 \times 10^{-4}$ to $1.0 \times 10^{-1} \mathrm{M}$, and the detection limit is $1.0 \times 10^{-5} \mathrm{M}$. The experiment results of potentiometric measurements and chronopotentiometry suggest that the electrode potential is very stable and the potential drift is significantly decreased.
\end{abstract}

Keywords: Chloride quantification, Electrochemistry, Poly(3,4-ethylenedioxythiophene), Sensor, Solid contact

\section{$\underline{\text { FULL TEXT }}$}

(C) 2017 The Authors. Published by ESG (www.electrochemsci.org). This article is an open access article distributed under the terms and conditions of the Creative Commons Attribution license (http://creativecommons.org/licenses/by/4.0/). 